\title{
Analysis of Length of Hospital Stay of Road Crash Patients in the Philippine General Hospital's Integrated Surgical Information System from 2008-2017
}

\author{
Teodoro J. Herbosa, MD, ${ }^{1}$ Jinky Leilanie Lu, MOH, $\mathrm{PhD}^{2}$ and Sophia Francesca Lu, MOS${ }^{3}$ \\ ${ }^{1}$ Department of Emergency Medicine and Department of Surgery, College of Medicine, University of the Philippines Manila \\ ${ }^{2}$ National Institutes of Health, University of the Philippines Manila \\ ${ }^{3}$ School of Labor and Industrial Relations, University of the Philippines Diliman
}

\begin{abstract}
Introduction. Mobility in the Philippines has increasingly become a major issue especially with the growing economy of the country. Collisions on the road cannot be entirely avoided; thus, we focus our efforts to reducing road crashes that result in death and serious injuries. To do this, we analyzed road crash patients brought to the Philippine General Hospital (PGH).
\end{abstract}

Objective. The study aimed to quantify how crash factors affect length of hospital stay (LOS) of patients brought to PGH, as well as to look for associations between the LOS and demographic and clinical variables.

Methods. This is a retrospective study using database of patients admitted in PGH from 2008 to 2017. The study focused on LOS, which was used as the dependent variable for Poisson regression and Kruskal-Wallis $\mathrm{H}$ tests. The determinants considered in the study are socio-demographic variables such as age, sex, civil status, victim type, vehicle type, patient classification, and region of incidence, as well as clinical variables such as consult type, outcome of the patient, body parts injured, Glasgow coma score (GCS), among others.

Results. We analyzed data of 4979 road crash patients from the PGH database. We found that civil status, age, patient classification, vehicle type, and province were associated with LOS. For the clinical variables, consult type, primary service, outcome of patient, body injuries, GCS and systolic blood pressure were found significant. Poisson regression suggests longer hospital stay for patients with injuries sustained in the head and neck $(R R=1.102$, $p<0.001)$, face $(R R=1.218, p<0.001)$, and extremity $(R R=1.673, p<0.001)$.

Conclusion. Results show that injury sustained in certain parts of the body such as head and neck, face, and extremity significantly affect LOS. Results also show that subgroups within demographic variables affect LOS. There is a need to address the ever-increasing number of road crash patients and implications to length of hospitalization.

Key Words: Road safety, road crash, length of stay

\section{INTRODUCTION}

Roads are the most predominant transport system in the Philippines. It accounts for $98 \%$ of passenger traffic and more than half of cargo traffic. In urban areas, vehicles such as private vehicles, public utility jeepneys, taxis, tricycle,

Corresponding author: Teodoro J. Herbosa, MD Department of Emergency Medicine and Department of Surgery

College of Medicine, University of the Philippines Manila

Taft Avenue, Ermita, Manila 1000, Philippines

Email: tjherbosa@up.edu.ph and pedicabs are mainly used on the road. Roads, being the most dominant transport system and poor quality, have an increasing number of vehicular accidents. ${ }^{1}$ In addition to unsafe roads, the World Health Organization (WHO) also recognized distracted driving, non-compliance with the use 
of motorcycle helmets, seatbelts and child restraints, drunkdriving and use of drugs, and unsafe vehicle as factors for road crash accidents. ${ }^{2}$

Between 20 to 50 million people suffer non-fatal injuries from road crashes, and these accidents claim lives. About 1.35 million people die every year from road accidents worldwide, mostly vulnerable road users such as pedestrians, cyclists and motorcyclists. ${ }^{2}$ In the Philippines, approximately 12,690 fatal road accidents happen every year and that constitutes 35 fatal accidents each day. ${ }^{3}$

Road traffic accidents are recorded higher in developing countries. In general, they pose significant economic burden. For the national economy, road traffic accidents lead to a loss of 3\% of the GDP yearly. For the victims, it poses a financial burden through hospital care costs and decreased productivity due to injuries and worse, even death. Road traffic accidents are the $8^{\text {th }}$ leading cause of death of younger adults and children aged 5 to 29 worldwide, greatly affecting those adults under the prime working ages. ${ }^{2}$

The Decade of Action for Road Safety (2011-2020) established in the UN General Assembly Resolution 64/255 had five pillars to "accelerate coordinated international action" in the reduction of road accident-related fatalities and injuries. The five pillars include: 1) road safety management; 2) safer roads and mobility; 3) safer vehicles; 4) safer road users; and 5) post-crash response. Pillar 5 focuses on provision of the key elements of post-crash support from the scene, treatment facilities and/or hospitals, and until follow-up: emergency care and rehabilitation for injury, mental health care, legal support, and data on crashes and injuries. ${ }^{4}$

Injuries and outcomes from road traffic accidents affect the hospital length of stay (LOS) of patients. Studies showed that severe injuries result in longer $\operatorname{LOS}^{5,6}$ and that road crashes involving trucks, buses and cars result in higher injury severity score (ISS) and increased hospital stay. ${ }^{7}$ A longer LOS for patients with severe trauma increases the risk of developing complications by seven times as compared to patients with moderate trauma, ${ }^{5}$ further aggravating the burden for the patient. A longer LOS has adverse effects resource-wise as prolonged stay of patients in hospitals poses economic burden through reduced productivity of the victim. In addition, increasing hospital costs ${ }^{5}$ is a major problem for marginalized people in our society.

A study on the social and economic burden of road traffic injuries in the Philippines estimated the cost of death and injuries in 2014 due to accidents in the road resulted to be USD 24.43 M on medical costs alone. In addition, the cost for lost productivity due to illnesses and injuries amounts to USD $534.184 \mathrm{M}^{8}{ }^{8}$ Thus, resource utilization, quality of care and costs are important factors determined by LOS ${ }^{9}$ in relation to these accidents. This study analyzes the LOS of road crash patients admitted in the Philippine General Hospital (PGH) from 2008-2017 using the Integrated Surgical Information System (PGH-ISIS) database. The specific objectives are: 1 ) to determine how crash factors affect LOS of patients brought to PGH; and 2) to determine associations between the LOS and demographic and clinical variables, and patient history.

\section{METHODS}

This is a retrospective study of patients admitted to PGH from 2008 to 2017. The Philippine General Hospital (UP-PGH) is a tertiary state-owned hospital operated by the University of the Philippines Manila. It is designated as the National University Hospital, and the national government referral hospital. The UP-PGH serves up to 600,000 patients every year. The PGH-ISIS database houses clinical abstracts of patients with trauma admitted to the $\mathrm{PGH}$, from the emergency room to inpatient care.

We included road crash patients admitted, discharged, or died in the PGH and is encoded in the PGH-ISIS portal from January 1, 2008 to December 31, 2017. We excluded: road crash patients who were not encoded in the PGH-ISIS; and patients discharged from PGH before January 1, 2008.

The researchers requested access to the PGH-ISIS portal after securing an approval from the Department of HealthSingle Joint Research Ethics Board (DOH-SJREB) and UP Manila Research Ethics Board (UPM-REB). This guarantees that the researchers involved in the study followed ethical practices and has ensured the confidentiality of patients whose data was included for the study was preserved. Once the request for access to the portal was approved by PGHISIS, research assistants who have health training such as nurses were assigned to encode data from the clinical abstracts to a pre-designed template in Microsoft Excel.

The PGH-ISIS is a system to digitally store clinical abstracts of patients admitted in PGH's surgery department, and only includes trauma patients. The researchers only had access to road crash patients in the PGH-ISIS database. The research assistants manually tracked, cross-checked, and cleaned the data. The data subset from 2008 to 2017 of the PGH-ISIS was used for the analysis of patient LOS. The data encoded in Microsoft Excel was converted to an SPSS file in preparation for statistical analyses. Multiple statistical approaches were made to analyze variables in the ISIS dataset.

The dependent variable was the patient's LOS in days. The independent variables were demographic variables (age, sex, region, province, city, admission date, service, consult type, patient classification, and LOS), history of the patient (mechanism of injury [MOI], place of injury [POI], date of injury (DOI), and time of injury [TOI] and body parts injured) and clinical variables (blood pressure levels, heart rate, respiratory rate, and Glasgow coma score [GCS]). We attempted to include alcohol and drug intake, and seatbelt and helmet use but the significant amount of missing data hindered statistical analysis.

LOS was a count variable that indicated the number of days the patient was admitted in the hospital before 


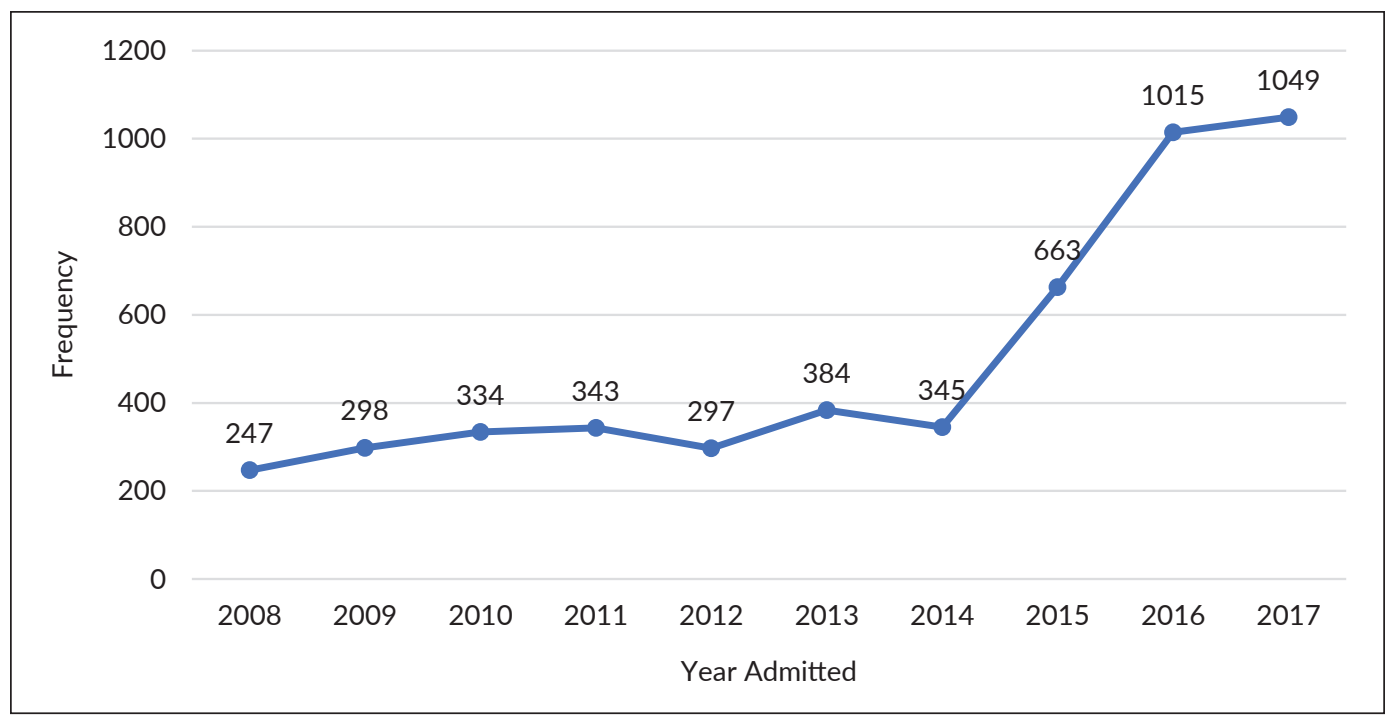

Figure 1. Road crash victim admissions per year based on PGH-ISIS database.

being discharged or dying. If variables were not normally distributed, we used non-parametric tests such as MannWhitney U and Kruskal-Wallis tests. Significance level was set at $95 \%$.

The variables were also considered for Poisson regression, and selected for the final model using forward selection.

\section{RESULTS}

\section{Socio-demographic Characteristics}

The total number of road crash patients in the PGHISIS database was 4979. The admissions per year of road crash patients increased from 247 in 2008, to 1049 in 2017, which was more than a $400 \%$ increase (Figure 1).

The most commonly involved age group was $20-29$ years old $(31 \%, \mathrm{n}=1,513)$, followed by the $30-39$ years old $(21 \%$, $\mathrm{n}=1,026)$. The two youngest age groups made up $22.6 \%$ $(\mathrm{n}=1,105)$. The average age was 30.8 years \pm 15.67 with the oldest being an 89-year-old.

Collision involving vehicles was the most common mechanism of injury of road crash victims $(48 \%, \mathrm{n}=874)$, followed by collision involving pedestrians $(24 \%, n=426)$, and damage to property only $(28 \%, \mathrm{n}=507)$. There was missing data $(63.7 \%)$ on mechanism of injury.

For the place of injury, it is notable that a huge proportion of patients in the dataset came from the province of Cavite (35.9\%), followed by Metro Manila $4^{\text {th }}$ district $(16.8 \%)$, and the province of Laguna (12\%). However, $72.9 \%$ of the ISIS dataset has missing values on the place of injury. Of the remaining 27.1\% (1348) cases, 1288 (25.9\%) came from Region III, NCR, and Region IV-A.

Majority $(61 \%, n=807)$ of the reported victim type was the driver. This was followed by pedestrian $(28 \%, \mathrm{n}=373)$ and passengers $(11 \%, \mathrm{n}=151)$. However, $73.3 \%$ of the ISIS dataset had missing values on victim type.

\section{Pattern of Injuries}

Majority (74\%) had a GCS score of 15 . and only 6\% had a GCS score of less than 8. Only 19.5\% (968) of the whole dataset has data on GCS scores of patients (Figure 2).

Meanwhile, the average GCS of the patients sampled was $13.88 \pm 2.509$ with 3 as the minimum and 15 as the maximum GCS scores (Table 2).

The body parts injured is one of the more complete variables in the database with only $3.1 \%$ missing. Majority (85.86\%) of patients brought in PGH suffered injuries in multiple body body parts. The most commonly reported injury was external injury (45.98\%), followed by injury in the extremities (32.25\%) (Figure 3).

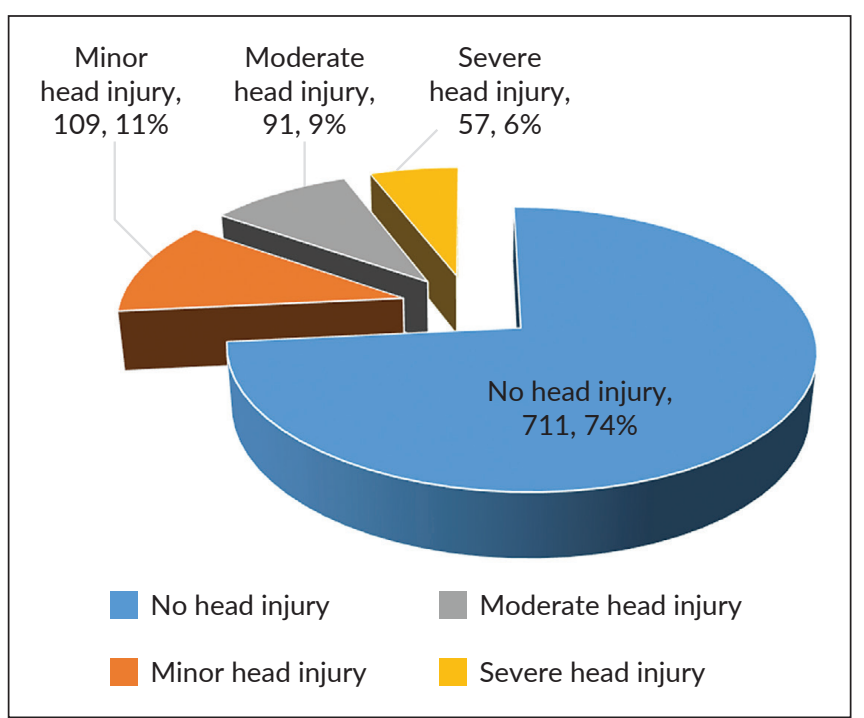

Figure 2. Distribution of the Glasgow coma score of road crash patients admitted from 2008 to 2017 based on PGH-ISIS database. 


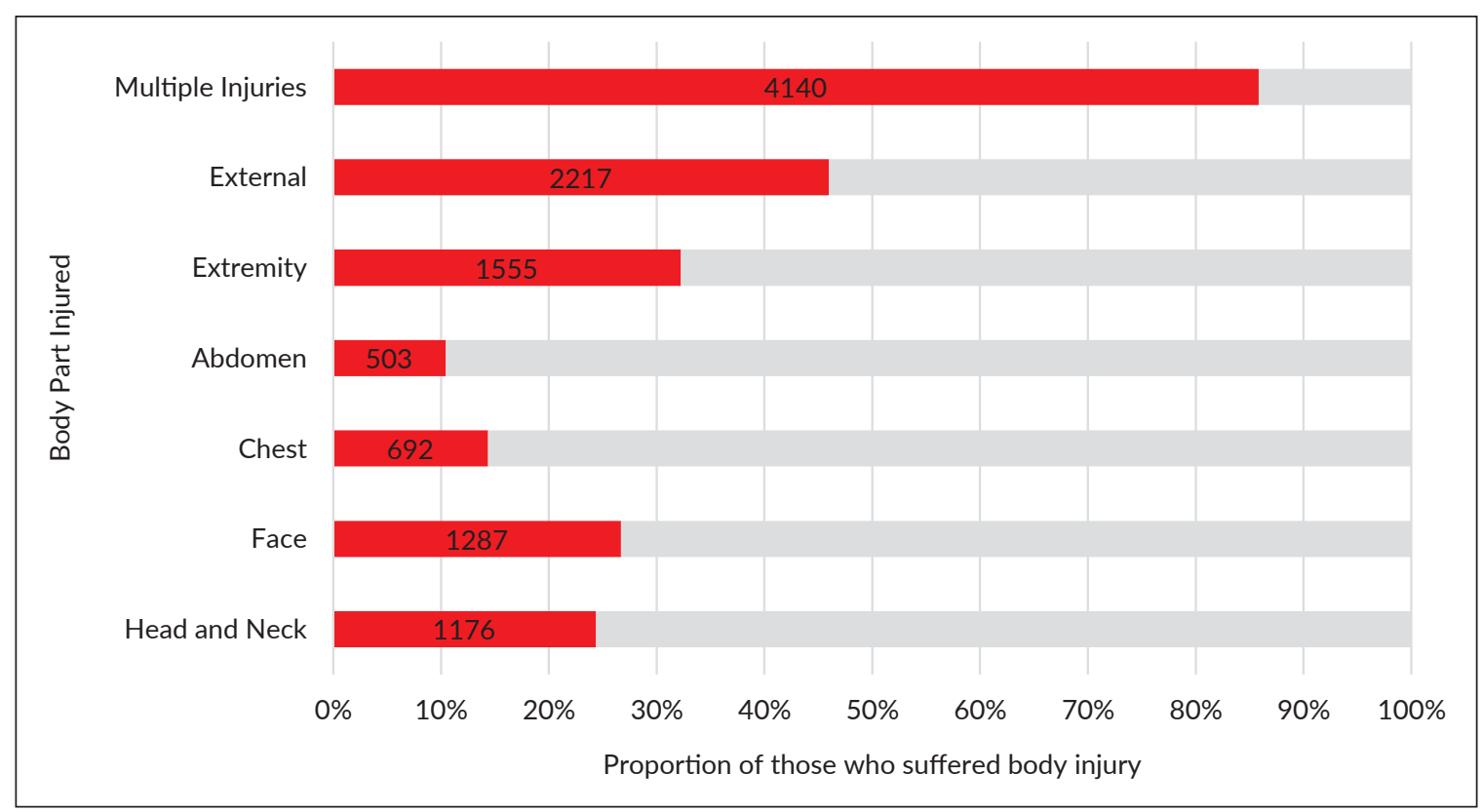

Figure 3. Distribution of body parts injured of road crash patients admitted from 2008 to 2017 based on PGH-ISIS database.

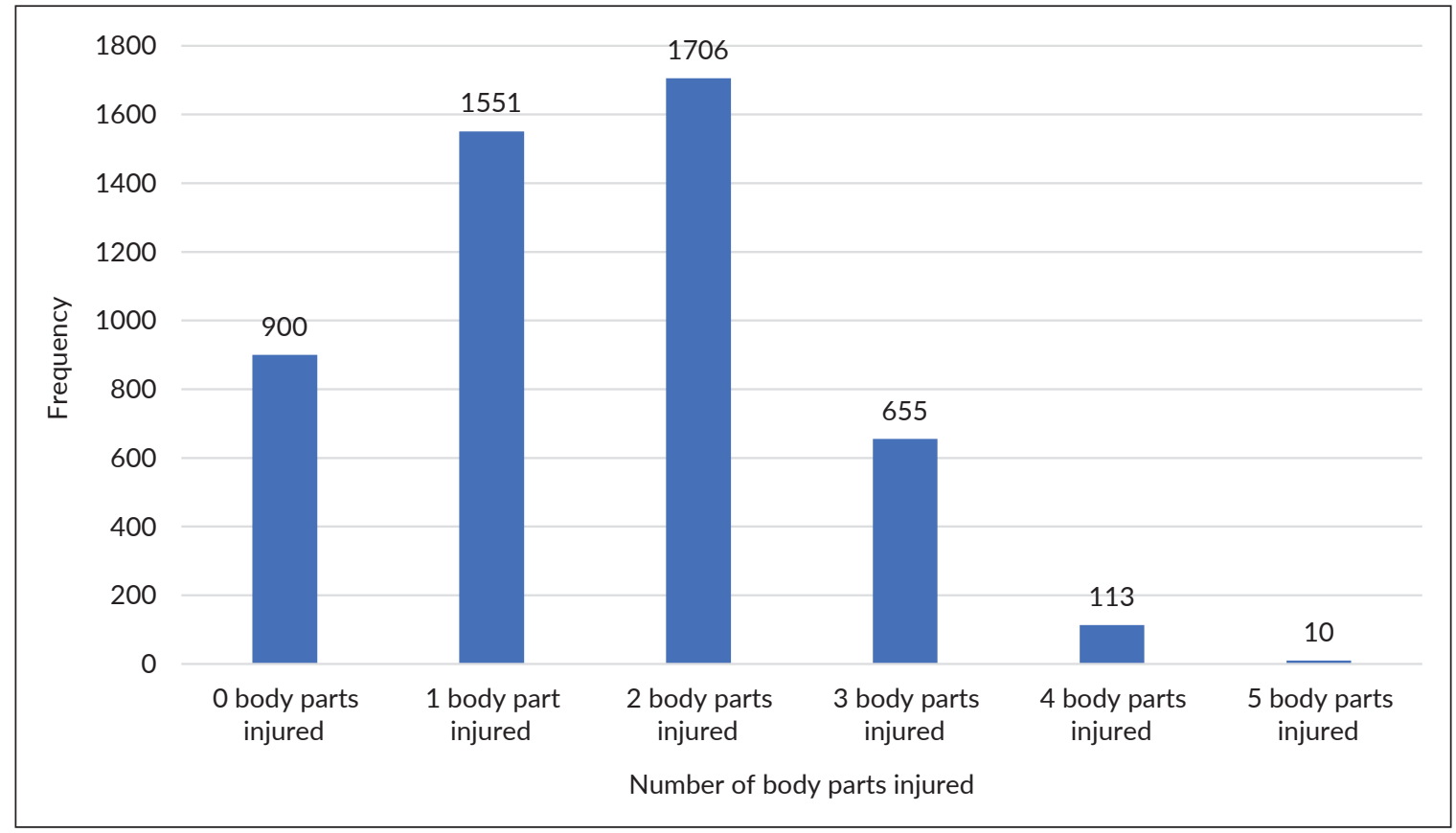

Figure 4. Distribution of number of body parts injured of road crash patients admitted from 2008 to 2017 based on PGH-ISIS database.

Most patients had injuries on one $(31.2 \% ; \mathrm{n}=1,551)$ or two body parts $(34.3 \% ; n=1,706)$. On the other hand, $900(18.2 \%)$ patients did not have any body parts injured (Figure 4).

The time elapsed post injury (in minutes) was the time from the incident to the time upon reaching the hospital.
The mean time elapsed post injury was 2429.563 minutes \pm 7140.33 (range is from 10-86400) or roughly 119.86 hours before the patient was transported from the site of accident to the hospital. However, this may be affected by other factors such as referrals from other hospital to the site of the study. The average stay in the hospital was 10.77 days \pm 46.37 . 


\section{Determinants of Length of Hospital Stay}

Civil status, age, patient classification, vehicle type, and province of residence were significantly associated with LOS using Mann-Whitney $U$ and Kruskal-Wallis tests (Table 1 and Table 2). Married patients had a higher mean rank, which means longer hospital days on average. Children had the shortest hospital stay compared to other age groups. Paying patients had significantly longer hospital stay than charity patients.

Three types of vehicles were significantly associated with LOS and ranked highest: "kuliglig" (vehicle composed of two-wheeled tractor pulled by a two-wheeled tractor), followed by trucks, and then buses. The provinces of residence associated with the longest hospital stay were Palawan, Nueva Vizcaya, Samar, and Isabela. Batangas was the lowest ranked. However, it should be noted that the huge number of categories in provinces might have caused spurious association. Difference in the LOS based on sex and victim type were not significant (Table 1 ).

Consult type, primary service, outcome of patient, body injuries, GCS, and systolic blood pressure (SBP) were significant clinical variables. The LOS for elective patients was significantly higher than emergency patients. The Surgery on Demand (SOD) group and pediatric surgery group had significantly lower hospital stay. The departments with the longest hospital stay were from Orthopedics, Burn, and Obstetrics and Gynecology. Patients who recovered had significantly longer hospital stay than those who died and those who had unchanged status. Patients who incurred injuries to the head and neck, face, chest, abdomen, and extremity all had significantly longer hospital stay than those with other body parts injured. Those who did not have external injuries had significantly shorter hospital stay than those who did.

GCS was significantly different among groups, with those with minimal brain injury having the longest hospital stay. Those without brain injury and those with severe brain injury had almost the same mean rank. Finally, those with abnormally low SBP levels have significantly lower hospital stay than those who have normal and abnormally high SBP levels. The differences in the time of the day for admission in hospital, respiratory rate, and heart rate were not significant (Table 3).

There was increased relative risk of experiencing longer hospital days in patients with head and neck injury (by 10.2\%) and face injury (by 21.8\%), while a reduced relative risk was shown in those with chest injury by $16.7 \%$, and abdomen injury by $6.6 \%$. Patients with extremity injury had an increased relative risk of experiencing longer hospital days by $67.3 \%$. Patients with abnormal SBP levels had increased relative risk of experiencing longer hospital days by $4.6 \%$, while those with abnormal diastolic levels had decreased relative risk 17.2\%. Lastly, those who had abnormal respiratory rate have decreased relative risk of experiencing longer hospital days $8.7 \%$ (Table 3).

\section{DISCUSSION}

The LOS is an important indicator of the effectiveness of the emergency hospital management. ${ }^{10,11}$ Reduced hospital stay is known to improve healthcare delivery, decreases the risk for complications, infections, and medication side effects, ${ }^{11}$ as well as reduces hospital costs on the side of the road traffic accident victims. ${ }^{12}$ The average length of stay of road crash patients from 2008 to 2017 included in the PGH-ISIS database was 10.77 days. This is similar to studies among hospitalized road traffic victims in Jamaica $(10 \text { days } \pm 8 \text { days })^{13}$ and in Ethiopia (11.16 days). ${ }^{14}$ This study in the Philippine setting showed that length of stay (LOS) in the hospital was significantly influenced by both clinical and non-clinical variables. Significant nonclinical variables were civil status, age, patient classification, vehicle type and province of residence; while significant clinical variables were consult type, primary service, patient outcomes, body injuries, GCS and SBP.

\section{Socio demographic Determinants of LOS}

This study showed that married road crash patients were most likely to incur longer hospital admission stays. This is similar to the findings in Iran among wherein married patients had longer hospital stay than their single counterparts. ${ }^{15}$ However, these were in contrast with the findings of Hayes et al. (2016) and Konda et al. (2020) who both found that single patients had longer hospital stays due to the lack of social support. ${ }^{16,17}$ More so, single patients were found to be more engaged in risky road behaviors because they have no dependents to support, nor they have properties and investments to protect. ${ }^{18}$

This study also showed that elderly ( $\geq 65$ years old) had the longest hospital stay followed by the prime working age (55-64 years old) while the group with the least LOS were children (0-14 years old). This is also the same with several studies. ${ }^{7,9,15}$ Older adults (65 years and older) are more susceptible to sustaining severe injuries. This is because the elderly experience cognitive and physical deterioration against environmental threats compared to the younger groups. ${ }^{7}$ More so, the rate of recovery of younger patients are better than that of their older counterparts, ${ }^{19}$ which can potentially shorten their LOS.

This study also showed that the greatest number of admissions were between the age range of 20-29 years old and 30-39 years old. This is supported by a study of Regev, Rolison and Moutari (2018) that crash risks are higher in the age range of 21-29 years old and the risk decreases as age increases. ${ }^{20}$ This may be attributed to the risky behavior of these age groups. A report in the United States in 2017 showed that drivers within the age range of 19-24 years old (88.4\%) to 25-39 years old (79.2\%) were the most likely to be engaged in speeding, red light running or distracted driving. ${ }^{21}$ 
Table 1. Distribution of length of hospital stay analysis based on socio-demographic variables

\begin{tabular}{|c|c|c|c|c|}
\hline Variable & Variable Levels & Mean Rank & Test Statistic & p-value \\
\hline \multirow[t]{2}{*}{ Sex } & Male & 2386.55 & $1654209.00^{*}$ & 0.07456 \\
\hline & Female & 2296.28 & & \\
\hline \multirow[t]{2}{*}{ Civil status } & Single & 2193.90 & $2211057.00^{*}$ & 0.00015 \\
\hline & Married & 2345.24 & & \\
\hline \multirow[t]{5}{*}{ Age } & Children (0-14) & 2034.27 & 40.91 & $<0.00001$ \\
\hline & Early Working Age (15-24) & 2410.86 & & \\
\hline & Mature Working Age (25-54) & 2423.34 & & \\
\hline & Prime Working Age (55-64) & 2435.78 & & \\
\hline & Elderly (65 above) & 2445.61 & & \\
\hline \multirow{2}{*}{$\begin{array}{l}\text { Patient } \\
\text { classification }\end{array}$} & Charity & 2342.40 & $568411.00^{*}$ & $<0.00001$ \\
\hline & Pay & 3066.90 & & \\
\hline \multirow[t]{9}{*}{ Vehicle type } & Pedicycle, Bicycle & 640.75 & 17.01 & 0.03000 \\
\hline & Motorcycle & 617.46 & & \\
\hline & Tricycle & 621.92 & & \\
\hline & Car & 554.69 & & \\
\hline & Jeepney & 599.94 & & \\
\hline & Bus & 871.75 & & \\
\hline & Van & 599.50 & & \\
\hline & Truck & 885.32 & & \\
\hline & Kuliglig & 1128.00 & & \\
\hline \multirow[t]{3}{*}{ Victim type } & Driver & 653.06 & 0.36 & 0.83502 \\
\hline & Passenger & 662.08 & & \\
\hline & Pedestrian & 667.03 & & \\
\hline \multirow[t]{29}{*}{ Province } & Metro Manila & 620.03 & 58.97 & 0.00055 \\
\hline & Cavite & 634.77 & & \\
\hline & Bulacan & 746.71 & & \\
\hline & Pangasinan & 617.50 & & \\
\hline & Batangas & 831.63 & & \\
\hline & Rizal & 672.92 & & \\
\hline & Mindoro Oriental & 432.43 & & \\
\hline & Mindoro Occidental & 691.50 & & \\
\hline & Quezon Province & 817.80 & & \\
\hline & Laguna & 695.99 & & \\
\hline & Romblon & 512.63 & & \\
\hline & Sorsogon & 311.00 & & \\
\hline & Tarlac & 686.88 & & \\
\hline & Aurora & 533.50 & & \\
\hline & Pampanga & 887.46 & & \\
\hline & Nueva Ecija & 943.21 & & \\
\hline & Nueva Vizcaya & 1046.00 & & \\
\hline & Batangas & 24.50 & & \\
\hline & Cagayan & 642.75 & & \\
\hline & Palawan & 1059.75 & & \\
\hline & Isabela & 1025.88 & & \\
\hline & Marinduque & 734.50 & & \\
\hline & Bataan & 222.50 & & \\
\hline & Zambales & 515.00 & & \\
\hline & Catanduanes & 800.88 & & \\
\hline & Camarines Sur & 734.50 & & \\
\hline & Masbate & 466.25 & & \\
\hline & Samar & 1041.50 & & \\
\hline & Leyte & 749.00 & & \\
\hline
\end{tabular}


LoS in PGH for road crash patients

Table 2. Distribution of hospital length of stay analysis based on clinical variables

\begin{tabular}{|c|c|c|c|c|}
\hline Variable & Variable Levels & Mean Rank & Test Statistic & p-value \\
\hline \multirow[t]{2}{*}{ Consult type } & Emergency & 2348.57 & 516026.50 & $<0.000001$ \\
\hline & Elective & 3066.78 & & \\
\hline \multirow[t]{19}{*}{ Primary service } & Trauma & 2557.04 & 1293.71 & $<0.000001$ \\
\hline & Plastic & 3105.53 & & \\
\hline & TCVS & 2928.39 & & \\
\hline & Orthopedics & 3686.69 & & \\
\hline & Urology & 1972.07 & & \\
\hline & NSS & 3031.74 & & \\
\hline & GS1 & 3337.58 & & \\
\hline & GS2 & 3213.79 & & \\
\hline & GS3 & 2772.58 & & \\
\hline & Pediatric Surgery & 1577.60 & & \\
\hline & Pediatrics & 2613.45 & & \\
\hline & Internal Medicine & 3191.43 & & \\
\hline & Burn & 3827.57 & & \\
\hline & Rehab & 3349.94 & & \\
\hline & SOD & 692.50 & & \\
\hline & Obstetrics and Gynecology & 1995.50 & & \\
\hline & ENT & 3672.61 & & \\
\hline & Ophthalmology & 1884.50 & & \\
\hline & Family Medicine & 2881.90 & & \\
\hline \multirow{3}{*}{$\begin{array}{l}\text { Outcome of } \\
\text { patient }\end{array}$} & Died & 1742.52 & 181.88 & $<0.000001$ \\
\hline & Recovered & 2488.71 & & \\
\hline & Unchanged & 1568.32 & & \\
\hline \multirow{2}{*}{$\begin{array}{l}\text { Head and } \\
\text { neck injury }\end{array}$} & No & 2326.76 & 1895803.50 & $<0.000001$ \\
\hline & Yes & 2556.60 & & \\
\hline \multirow[t]{2}{*}{ Face injury } & No & 2278.42 & 1865928.00 & $<0.000001$ \\
\hline & Yes & 2667.74 & & \\
\hline \multirow[t]{2}{*}{ Chest injury } & No & 2346.78 & 1253098.00 & 0.000009 \\
\hline & Yes & 2597.99 & & \\
\hline \multirow[t]{2}{*}{ Abdomen injury } & No & 2336.17 & 866522.00 & $<0.000001$ \\
\hline & Yes & 2782.46 & & \\
\hline \multirow[t]{2}{*}{ Extremity injury } & No & 2164.63 & 1772631.00 & $<0.000001$ \\
\hline & Yes & 2842.94 & & \\
\hline \multirow[t]{2}{*}{ External injury } & No & 2431.47 & 2698316.00 & 0.0085916 \\
\hline & Yes & 2326.73 & & \\
\hline \multirow{4}{*}{$\begin{array}{l}\text { Glasgow } \\
\text { coma score }\end{array}$} & No Brain Injury & 464.76 & 13.48 & 0.0037124 \\
\hline & Minimal Brain Injury & 560.58 & & \\
\hline & Moderate Brain Injury & 521.97 & & \\
\hline & Severe Brain Injury & 465.65 & & \\
\hline \multirow{3}{*}{$\begin{array}{l}\text { Systolic blood } \\
\text { pressure }\end{array}$} & Abnormally Low & 455.27 & 12.50 & 0.0019258 \\
\hline & Normal & 668.28 & & \\
\hline & Abnormally High & 649.31 & & \\
\hline \multirow[t]{3}{*}{ Respiratory rate } & Abnormally Low & 535.21 & 0.21 & 0.8997469 \\
\hline & Normal & 570.32 & & \\
\hline & Abnormally High & 564.95 & & \\
\hline \multirow[t]{3}{*}{ Heart rate } & Abnormally Low & 523.22 & 0.54 & 0.7650669 \\
\hline & Normal & 578.57 & & \\
\hline & Abnormally High & 584.58 & & \\
\hline
\end{tabular}


LoS in PGH for road crash patients

Table 3. Poisson regression model for hospital length of stay of road crash patients admitted from 2008-2017 based on PGH-ISIS database ( $n=1,227)$

\begin{tabular}{lcccc} 
Independent Variables & Parameter Estimate & Std. Error & p-value & Risk Ratio \\
\hline Head and neck injury & 0.097 & 0.0184 & $<0.001$ & 1.102 \\
Face injury & 0.197 & 0.0174 & $<0.001$ & 1.218 \\
Chest injury & -0.183 & 0.0211 & $<0.001$ & 0.833 \\
Abdomen injury & -0.069 & 0.0226 & 0.002 & 0.934 \\
Extremity injury & 0.515 & 0.0161 & $<0.001$ & 1.673 \\
External injury & -0.050 & 0.0156 & 0.001 & 0.951 \\
Systolic BP & 0.045 & 0.0190 & 0.017 & 1.046 \\
Diastolic BP & -0.189 & 0.0191 & $<0.001$ & 0.828 \\
Heart rate & 0.034 & 0.0199 & 0.084 & 1.035 \\
Respiratory rate & -0.091 & 0.0184 & $<0.001$ & 0.913 \\
\hline
\end{tabular}

It is also important to note that the motorcycle was the most involved vehicle, which is consistent to studies in other developing countries. ${ }^{22-24}$ The demand and usage of motorcycles in developing countries could be attributed to its low cost as well as its easy mobility in areas with heavy vehicular traffic. ${ }^{25}$ In addition, the WHO reported that half $(57.60 \%)$ of the total vehicle registrations in the Philippines in 2016 consisted of motorized 2- and 3wheelers. ${ }^{26}$ Therefore, this vehicle type should be scrutinized when formulating new policies regarding road safety.

Most of the cities with the longest hospital stay were in provinces in rural areas (Palawan, Nueva Vizcaya, Samar, and Isabela). ${ }^{27} \mathrm{~A}$ study conducted in Taiwan showed that patients involved in road crash accidents that occurred in rural areas have longer LOS. ${ }^{7}$ Moreover, as compared to urban areas, road accidents that occurred in rural areas result in more fatal outcomes. ${ }^{28}$ These may be caused by the unacceptable road conditions in the rural areas and unsafe behavior of the driver. ${ }^{7,29}$ In addition, it was found that less people use seatbelts and helmets in rural areas. ${ }^{28,29}$ In a study involving motor vehicular accidents that resulted in traumatic brain injuries, LOS was longer by $55.03 \%$ in drivers who sustained brain injury and did not wear than their counterparts. ${ }^{19}$ It is also worth mentioning that more than half $(61 \%)$ of the patients admitted in this study were drivers.

\section{Clinical Determinants of LOS}

The significant clinical variables in this study are the patient's consult type, primary service, outcome of the patient, location of body injuries, GCS, and SBP. Patients who sought elective consultation stayed longer in the hospital than emergency patients. This is in contrast to a study in France that showed elective type of admission resulting in shorter hospital stay and higher revenues per day for the hospital..$^{30}$ An earlier study also established that the LOS of elective patients is shorter by approximately 2 days than that of acute admission patients. ${ }^{31}$

Patients with extremity injuries had longer length of stay followed by head and neck, and face injuries. A study in Saudi Arabia identified the location of fractures sustained by patients involved in road traffic accidents as: femur, humerus, spine, skull, ribs, and tibia. ${ }^{32}$ Traumatic cases in the upper and lower limb, spine, clavicle, pelvis and soft tissue injuries also lengthen LOS. ${ }^{33}$ Bone fractures result in longer LOS because they take time to heal. ${ }^{34}$ Patients admitted under the orthopedic department had the longest hospital stay. This is also consistent with the above studies as most of the injuries sustained during road traffic accidents involved orthopedic care and the LOS is dependent on the injuries obtained. Some orthopedic cases required surgery and surgical procedures were an important factor for determining LOS, ${ }^{6}$ with patients who have undergone surgeries being 5.36 times more likely to stay for another day in the hospital. ${ }^{9}$

On the other hand, patients with external injuries had the shortest hospital stay. A study in Papua New Guinea among road traffic patients showed that soft tissue injuries were the most common injuries sustained by the patients. ${ }^{35}$ The short hospital stay may be attributed to the less severe injuries sustained by patients with external injuries, such as scratches and slight confusion, which can be easily managed and result in early discharge..$^{35}$

In addition to external injuries, patients who suffered chest and abdomen injuries also had shorter length of stay. The chest and abdomen house the vital organs in the body and patients with organ injuries are slower to recover. This is because organ damage could result in fatal bleeding, internally and externally, as well as organ failure which result in negative prognosis, such as poor recovery and death. ${ }^{36}$

Patients with minimal brain injury (GCS 13-14) had longer LOS with increasing severity with the exception of GCS 15, which had a mean rank similar to that of severe brain injury; an unusual finding. In a study among motor vehicle accident victims in Saudi Arabia, GCS was a measure of trauma associated with mortality and length of hospital admission especially when GCS was low. ${ }^{37}$ SBP appeared to influence the LOS as well. This study showed that patients with abnormally low SBP levels tend to have shorter LOS than those with normal SBP. Some studies 
showed that SBP, specifically low SBP, is a predictor for prolonged hospital LOS. ${ }^{38,39}$ Among trauma patients, the relationship between heart rate and SBP was also studied: hypotension-bradycardia patients $(\mathrm{SBP}<90 \mathrm{mmHg}$ ), (HR $<60 \mathrm{bpm}$ ) had higher mortality rate (80\%) than those with normal SBP and HR.40 Thus, low SBP indicate greater risk for mortality, which can shorten length of stay. ${ }^{9,41}$

Patients who recovered during the hospitalization had longer LOS than those who died and those with unchanged situation. This is supported by a study in Iran among trauma patients that $97.80 \%(\mathrm{n}=3,811)$ who were discharged alive had $\geq 3$ days of LOS. ${ }^{9}$ One study showed that among critically injured trauma patients, those who survived within first few days of hospitalization had longer ICU-LOS of $\geq 40$ days. ${ }^{41}$

The study is limited by the data that is available in PGHISIS online database. The system only includes patients that were admitted to the hospital, hence ER consults and ER deaths, pre-hospital deaths, and death on arrivals were excluded.

\section{CONCLUSION}

The study showed that demographic variables (married civil status; younger age; pay patient classification; kuliglig, truck and bus vehicle type; and residents of Palawan, Nueva Vizcaya, Samar and Isabela, and clinical variables (elective consult type; burn, ENT and orthopedic primary service; recovered as outcome of patient; body injuries to the head and neck, face, chest, abdomen, extremities, and those without external injuries; high GCS; and normal SBP) were significant associated with longer hospital stay among road crash patients at the PGH. Road traffic accidents are a public health and economic burden and increasing length of hospitalization adds to the already overstretched hospital care.

\section{Statement of Authorship}

All authors contributed in the conceptualization of work; acquisition and analysis of data; drafting and revising; and final approval of the version to be published.

\section{Author Disclosure}

All authors declared no conflicts of interest.

\section{Funding Source}

This study was funded by the Emerging Interdisciplinary Research (EIDR) Program of the University of the Philippines System.

\section{REFERENCES}

1. Asian Development Bank. Philippines: Transport Sector Assessment, Strategy, and Road Map [Internet]. Mandaluyong: Asian Development Bank; 2012 [cited $2021 \mathrm{Apr}$. Available from: https:/www.adb.org/ sites/default/files/institutional-document/33700/files/philippinestransport-assessment.pdf.
2. World Health Organization. Road Traffic Injuries. Geneva: WHO; c2021 [Internet]. updated $2020 \mathrm{Feb} 7$. [cited $2021 \mathrm{Apr}$. Available from: https://www.who.int/news-room/fact-sheets/detail/ road-traffic-injuries.

3. Umali A. Making roads safer for children in the Philippines Mandaluyong: UNICEF Philippines; c2021 [Internet]. updated 2019 December 13 [cited 2021 Apr]. Available from: https:// www.unicef.org/philippines/stories/making-roads-safer-childrenphilippines\#: : text $=$ Road $\% 20$ traffic $\% 20$ injury $\% 20$ has $\% 20$ become,12\%2C690\%20fatalities\%20in\%20a\%20year.

4. World Health Organization. Post-Crash Response: Supporting those affected by road traffic crashes. Geneva: World Health Organization [Internet]. 2016 [cited 2021 Jul]. Available from: https://www.who.int/ publications-detail-redirect/post-crash-response-supporting-thoseaffected-by-road-traffic-crashes.

5. Berhe RH, Redae G, Jemal Y, Mohammed AN. Time to recovery and determinants of trauma among patients admitted to Lemlem Karl Hospital Maichew, Southern Tigray, Ehiopa: a retrospective cohort study. Int J Biomed Sci Eng. 2020 Jun; 8(2):11-8.

6. Beppu S, Hitosugi M, Ueda T, Koh M, Nishiyama K. Factors influencing the length of emergency room stay and hospital stay in non-fatal bicycle accidents: A retrospective analysis. Chin J Traumatol. 2021 May; 24(3):148-52.

7. Lam C, Pai CW, Chuang CC, Yen YC, Wu CC, Yu SH, et al. Rider factors associated with severe injury after a light motorcycle crash: A multicentre study in an emerging economy setting. PLoS One. 2019 Jun 28; 14(6):e0219132.

8. Lam HY, Rivera AS, Macalino JU, Quebral JD, Cheng KJ, Miguel RT. Estimating the social and economic burden of road traffic injuries in the Philippines. Acta Med Philipp. 2018 Sep 28; 52(5): 423-8.

9. Kashkooe A, Yadollahi M, Pazhuheian F. What factors affect length of hospital stay among trauma patients? A single-center study, Southwestern Iran. Chin J Traumatol. 2020 Jun; 23(3):176-80.

10. Ahmed AA, Ibro SA, Melkamu G, Seid SS, Tesfaye T. Length of stay in the emergency department and its associated factors at Jimma Medical Center, Southwest Ethiopia. Open Access Emerg Med. 2020 Oct 9; 12:227-35.

11. Baek H, Cho M, Kim S, Hwang H, Song M, Yoo S. Analysis of length of hospital stay using electronic health records: A statistical and data mining approach. PLoS One. 2018 Apr 13; 13(4):e0195901.

12. Emamgholipour S, Raadabadi M, Dehghani M, Fallah-Aliabadi S. Analysis of hospital costs in road traffic injuries. Bull Emerg Trauma. 2021 Jan; 9(1):36-41.

13. Fletcher C, Mcdowell D, Thompson C, James K. Predictors of hospitalization and surgical intervention among patients with motorcycle injuries. Trauma Surg Acute Care Open. 2019; 4:e00326.

14. Woyessa AH, Heyi WD, Ture NH, Moti BK. Patterns of road traffic accident, nature of related injuries, and post-crash outcome determinants in western Ethiopia - a hospital-based study. Afr J Emerg Med. 2021 Mar; 11(1):123-31.

15. Khosravizadeh O, Vatankhah S, Bastani P, Kalhor R, Alirezaei S, Doosty F. Factors affecting length of stay in teaching hospitals of a middle-income country. Electron Physician. 2016 Oct 25; 8(10): 3042-7.

16. Hayes RM, Carter PR, Gollop ND, Reynolds J, Uppal H, Sarma J, et al. 108 The Impact of Marital Status on Mortality and Length of Stay in Patient Admitted with Myocardial Infarction. Heart. 2016; 102(Suppl 6):A77.

17. Konda SR, Gonzalez LJ, Johnson JR, Friedlander S, Egol KA. Marriage status predicts hospital outcomes following orthopedic trauma. Geriatr Orthop Surg Rehabil. 2020 Jan 22; 11:2151459319898648.

18. Teye-Kwadjo E. Risky driving behaviour in urban Ghana: the contributions of fatalistics beliefs, risk perception, and risk-taking attitude. Int J Health Promot Educ. 2019; 57(5):256-73.

19. Puro SS, Shen S, Neyens DM. Factors affecting hospital length of stay for drivers with traumatic brain injuries from motor vehicle crashes: South Carolina Case Study. Transp Res Rec. 2016 Jan; 2601:84-9. 
20. Regev S, Rolison JJ, Moutari S. Crash risk by driver age, gender, and time of day using a new exposure methodology. J Safety Res. 2018 Sep; 66:131-40.

21. Gross A. Young Millenials Top List of Worst Behaved Drivers. Chicago (IL): AAA; c2021 [Internet]. updated 2017 Feb 15. [cited 2021 Mar]. Available from: https://newsroom.aaa.com/2017/02/ young-millennials-top-list-worst-behaved-drivers/.

22. Gurung US, Singh G, Mishra M, Mondal S, Gaur A. Maxillofacial injuries related to road traffic accidents: a five-year multi center analysis. Craniomaxillofac Trauma Reconstr. 2019; 3:e61-6.

23. Boniface R, Museru L, Kiloloma O, Munthali V. Factors associated with road traffic injuries in Tanzania. Pan Afr Med J. 2016 Feb 19; 23:46.

24. Karkee R, Lee AH. Epidemiology of road traffic injuries in Nepal, 2001-2013: systematic review and secondary data analysis. BMJ Open. 2016; 6(4):e010757.

25. Dos Santos WJ, Coêlho VMDS, Bonfim CVD, de Ceballos AGDC. Alcohol and risky behavior in traffic among motorcyclists involved in accidents in a city in northeastern Brazil. Traffic Inj Prev. 2019; 20(3):233-7.

26. World Health Organization. Global Status Report on Road Safety 2018. Geneva: World Health Organization [Internet]. 2018. [cited 2021 Apr]. Available from: https://www.who.int/publications/i/item/ 9789241565684.

27. Philippine Statistics Authority. Urban Barangays in the Philippines (Based on $2010 \mathrm{CPH}$ ). Quezon City: Philippine Statistics Authority [Internet]. c2021 updated 2013 Jun 7. [cited 2021 Apr]. Available from: https://psa.gov.ph/content/urban-barangays-philippines-based2010-cph.

28. Cabrera-Arnau C, Prieto Curiel R, Bishop SR. Uncovering the behaviour of road accidents in urban areas. R Soc Open Sci. 2020 Apr 15; 7:191739.

29. Chang FR, Huang HL, Schwebel DC, Chan AHS, Hu GQ. Global road traffic injury statistics: Challenges, mechanisms and solutions. Chin J Traumatol. 2020 Aug; 23(4):216-8.

30. Casalino E, Perozziello A, Choquet C, Curac S, Leroy C, Hellmann R. Evaluation of hospital length of stay and revenues as a function of admission mode, clinical pathways including observation unit stay and hospitalization characteristics. Health Serv Manage Res. 2019 Feb; 32(1):16-25.

31. Majeed MU, Williams DT, Pollock R, Amir F, Liam M, Foong KS, et al. Delay in discharge and its impact on unnecessary hospital bed occupancy. BMC Health Serv Res. 2012 Nov 20; 12:410.
32. Aloudah AA, Almesned FA, Alkanan AA, Alharbi T. Pattern of fractures among road traffic accident victims requiring hospitalization: single-institution experience in Saudi Arabia. Cureus. 2020 Jan 3; 12(1):e6550. PubMed PMID: 32042524.

33. Mishra BN, Jha A, Maharjan E, Limbu M, Sah S, Gupta Y, et al. Length of stay of orthopaedic inpatients at a teaching hospital in Eastern Part of Nepal. JNMA J Nepal Med Assoc. 2015 Jul-Sep; 53(199):180-3.

34. Seid M, Azazh A, Enquselassie F, Yisma E. Injury characteristics and outcome of road traffic accident among victims at Adult Emergency Department of Tikur Anbessa specialized hospital, Addis Ababa, Ethiopia: a prospective hospital-based study. BMC Emerg Med. 2015 May 20; 15:10.

35. Kourouma K, Delamou A, Lamah L, Camara BS, Kolie D, Sidibé S, et al. Frequency, characteristics and hospital outcomes of road traffic accidents and their victims in Guinea: a three-year retrospective study from 2015 to 2017. BMC Public Health. 2019 Jul 31; 19(1):1022.

36. Tesfay K, Assefa M, Zenebe D, Gebremicael M, Kebede G, Gebrekirstos H. Road traffic injured patients with severe GCS and organ injury had a poor prognosis: a retrospective cohort study. BMC Public Health. 2019 Jun 13; 19:749.

37. Alshahrani MS. Effect of private versus emergency medical systems transportation in motor vehicle accident victims: Trauma Center Experience in Saudi Arabia.J Family Community Med. 2017 Jan-Apr; 24(1):30-3.

38. Daghistani TA, Elshawi R, Sakr S, Ahmed AM, Al-Thwayee A, AlMallah MH. Predictors of in-hospital length of stay among cardiac patients: A machine learning approach. Int J Cardiol. 2019 Aug 1; 288:410-7.

39. Stecker MM, Stecker M, Falotico J. Predictive model of length of stay and discharge destination in neuroscience admissions. Surg Neurol Int. 2017 Feb 6; 8:17.

40. Bhandarkar P, Munivenkatappa A, Roy N, Kumar V, Samudrala VD, Kamble J, et al. On-admission blood pressure and pulse rate in trauma patients and their correlation with mortality: Cushing's phenomenon revisited. Int J Crit Illn Inj Sci. 2017 Jan-Mar; 7(1):14-17.

41. Kisat MT, Latif A, Zogg CK, Haut ER, Zafar SN, Hashmi ZG, et al. Survival outcomes after prolonged intensive care unit length of stay among trauma patients: The evidence for never giving up. Surgery. 2016 Sep; 160(3):771-80. 